\title{
Prototipe Sistem Monitoring Penggunaan Daya Motor Listrik 3 Fasa Berbasis Java Programing
}

\author{
Akhyar Muchtar $^{1 *}$, Umar Muhammad ${ }^{2}$, Ainul Mariyah ${ }^{3}$ \\ ${ }^{1,2,3}$ Prodi Teknik Listrik Politeknik Bosowa \\ ”akhyar.muchtar@bosowa.co.id
}

\begin{abstract}
Dependence on power consumption (watts) of electricity at this time is very high, including the production processes in industry. The purpose of this study was to monitor power usage based arduino 3 phase and control power usage through the computer. This study used an experimental method to observe the results of current and voltage sensor readings. The design of the module uses a voltage sensor, a current sensor with type SCT 013000 $100 \mathrm{~A} / \mathrm{V}$, then fitted with the control microcontroller arduino uno $R 3,4$ channel relay module and display monitoring power usage of the Java programming language. The results of the monitoring module testing 3-phase electric power consumption is obtained percentage measurement error phase voltage $R$ value of $0.48 \%$, S phase voltage values of $2.90 \%$ and the value of the phase voltage $T$ of 1,39\%. The percentage level measurement error phase current $R$ value of $4.6 \%$, a current value of $4.6 \% S$ phase and T phase current value of $1.7 \%$. The percentage level measurement error $R$ phase power value of $4.49 \%$, the value of the phase $S$ of $2.03 \%$ and the value of the phase $T$ of $1.93 \%$.
\end{abstract}

Keywords: monitoring, current, voltage, power (watts)

\begin{abstract}
Abstrak
Ketergantungan dalam pemakaian daya (watt) listrik pada saat ini sangat tinggi, termasuk pada proses produksi di bidang industri. Tujuan dari penelitian ini untuk melakukan monitoring pemakaian daya listrik 3 fasa berbasis arduino dan mengendalikan pemakaian daya listrik melalui program monitoring. Penelitian ini menggunakan metode eksperimen dengan mengamati hasil pembacaan sensor arus dan sensor tegangan. Perancangan ini menggunakan sensor tegangan dan sensor arus dengan tipe sct-013-000 100A/1V, kemudian dilengkapi dengan pengontrolan mikrokontroller arduino uno R3, relay module 4 channel dan tampilan monitoring pemakaian daya listrik dari bahasa pemograman java. Hasil pengujian modul monitoring pemakaian daya listrik 3 fasa diperoleh persentase kesalahan pengukuran nilai tegangan fasa $R$ sebesar $0,48 \%$, nilai tegangan fasa $S$ sebesar 2,90\% dan nilai tegangan fasa $T$ sebesar $1,39 \%$. Tingkat persentasi kesalahan pengukuran nilai arus fasa $R$ sebesar 4,6 \%, nilai arus fasa $S$ sebesar 4,6 $\%$ dan nilai arus fasa $T$ sebesar $1,7 \%$. Tingkat persentasi kesalahan pengukuran nilai daya fasa $R$ sebesar $4,09 \%$, nilai daya fasa $S$ sebesar $2,09 \%$ dan nilai daya fasa $T$ sebesar $1,93 \%$.
\end{abstract}

Kata kunci: monitoring, arus, tegangan, daya (watt)

\section{Pendahuluan}

Energi listrik merupakan kebutuhan primer khususnya bagi kalangan industri.Sebanyak 30\% dari seluruh keperluan energi primer digunakan oleh kalangan industri. Ketergantungan industri ini dalam pemakaian energi listrik diperlukan untuk mendukung keberlangsungan produksi. Hal ini dapat dilihat dengan adanya penggunaan peralatan pendukung untuk mengefisienkan proses produksi dengan mengubah sistem manual menjadi otomatis yang tentunya membutuhkan energi listrik yang cukup besar [1]. 
Efisiensi proses produksi bagi industri bertujuan untuk meningkatkan daya saing serta keuntungan baik dari segi finansial maupun lingkungan. Khusus dari segi finansial, efisiensi proses produksi dengan memanfaatkan energi listrik akan memaksimalkan keuntungan. Dari segi lingkungan, proses produksi yang demikian akan membantu mengurangi polusi termal dan efek rumah kaca.

Penggunaan energi listrik disektor industri selama ini hanya dapat dilihat menggunakan alat ukur Kwh meter yang didistribusikan oleh PLN. Penggunaan alat tersebut tidak memberikan informasi secara detail tentang berapa penggunaan energi listrik pada tiap subitem yang terhubung pada Kwh. Jika dilihat dari data historinya, terkadang terjadi perubahan penggunaan energi yang mendadak turun karena adanya kerusakan mesin atau pemeliharaan yang tidak diketahui. Hal ini akan mengakibatkan terjadi pemborosan energi listrik. Oleh karena ini, diperlukan alat monitoring pada industri yang dapat memperlihatkan penggunaan energi listrik pada tiap subitem sehingga terlihat penggunaan energi listrik yang tidak efisien [2].

Prototipe sistem monitoring pengunaan daya listrik 3 fasa menggunakan sensor arus berbasis Arduino ini dirancang untuk mendapatkan informasi pemakaian daya listrik (watt) pada beban motor listrik 3 fasa secara realtime dan dapat dikontrol pada program monitoring kapan saja. Peralatan ini terdiri atas perangkat keras dan perangkat lunak yang saling terhubung sehingga informasi dan pengendalian pemakaian daya listrik pada beban motor listrik 3 fasa dapat dilakukan melalui komputer. Pengukuran daya semacam ini biasanya dilakukan secara manual dengan menggunakan alat ukur konvensional. Akan tetapi hasilnya terlalu lama untuk didapatkan. Prototipe sistem monitoring pengunaan daya listrik 3 fasa menggunakan sensor arus berbasis Arduino diharapkan dapat menggantikan sistem pengukuran yang dilakukan secara manual dengan memberikan hasil yang lebih maksimal.

Pada peragkat monitoring ini, terdapat rangkaian sensor, Arduino Uno dan program monitoring yang dibuat dengan menggunakan Bahasa pemograman java.Rangkaian sensor terdiri dari current transformer dan $A C$ to $A C$ Power Adapter. Arduino Uno digunakan sebagai proscessor untuk mengolah data pembacaan sensor. Program monitoring digunakan untuk menunjukkan hasil pembacaan sensor secara real time dan sekaligus dapat digunakan untuk mengontrol penggunaan energi listrik pada beban motor 3 fasa.

\section{Metoda Penelitian}

Metode yang digunakan dalam penelitian ini adalah metode eksperimen dengan model ADDIE yang terdiri dari beberapa tahap yaitu analisis, design, development, implementation dan evaluation [3].

Gambar 1 menunjukkan proses eksperimen yang dilakukan.

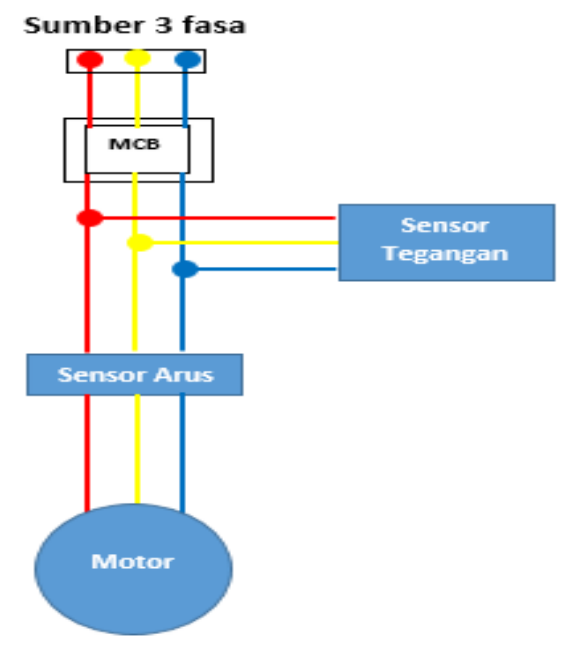

Gambar 1. Diagram Blok Sistem

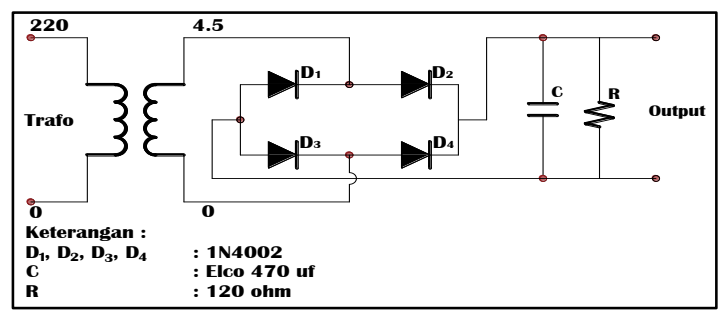

Gambar 2. Diagram Sensor Tegangan 
Pendeteksian tegangan menggunakan transformator 1 A dari 220 ACV yang diturunkan menjadi 4.5 ACV. Ilustrasi rangkaian diperlihatkan dalam Gambar 2. Setelah melalui diode bridge (penyearah), filter dan pembagi tegangan, dihasilkan tegangan DC yang berbanding lurus dengan naik turunnya tegangan listrik PLN. Tegangan 4.5 ACV disearahkan menjadi tegangan DC dengan kisaran nilai $\pm 4 \mathrm{VDC}$ melalui rangkaian penyearah, filter dan pembagi tegangan. Output tersebut dimasukkan ke pin analog input arduino.

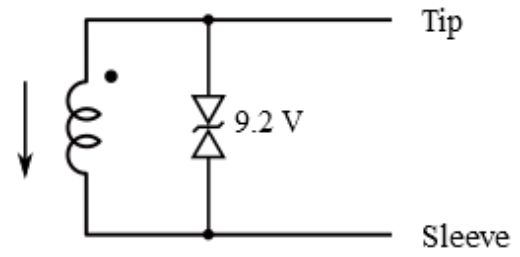

Gambar 3. Circuit Diagram Sensor Arus

Sensor seperti dalam Gambar 3 berperan sebagai pendeteksi nilai arus yang terukur dari beban. Komponen yang digunakan berupa sensor arus dengan tipe SCT 013-000 100A/1V. Sensor ini dilakukan kalibrasi pada library emonlib kemudian hasil dari kalibrasi tersebut yang menjadi input pin analog Arduino.

Perancangan tampilan modul monitoring pemakaian daya listrik (watt) 3 fasa menggunakan bahasa pemrograman java. Data hasil pengukuran sensor arus dan sensor tegangan akan diolah Arduino kemudian ditampilkan pada komputer. Gambar perancangan tampilan pada komputer seperti ditunjukkan dalam Gambar 4.

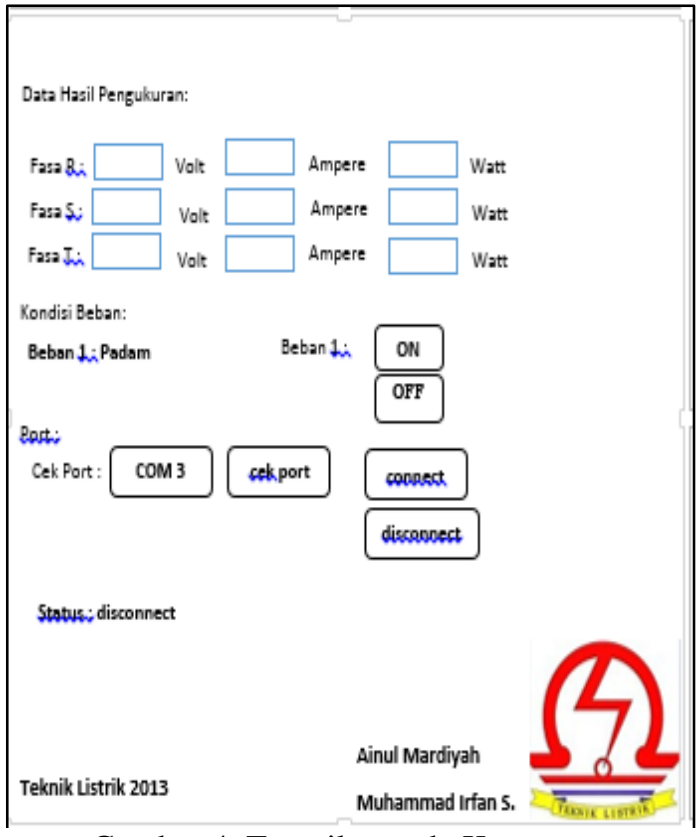

Gambar 4. Tampilan pada Komputer

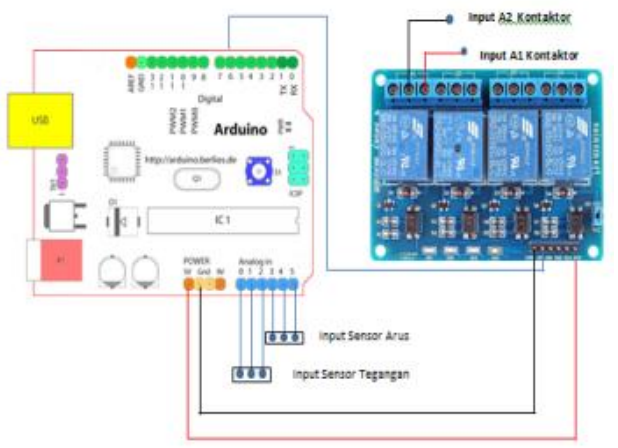

Gambar 5. Rangkaian Kontrol

Rangkaian kontrol modul seperti dalam Gambar 5, terdiri dari komponen board arduino uno, relay module 4 channel, sensor tegangan 1, sensor tegangan 2, sensor tegangan 3, sensor arus 1, sensor arus 2 dan sensor arus 3. Output kabel positif dari sensor tegangan 1, 2 dan 3 masuk pada analog input pin 0 , pin 1, pin 2 arduino. Ouput kabel positif sensor arus masuk pada analog input pin 3, pin 4, pin 5 arduino. Pin 6 digital input arduino masuk pada input pin 1 relay modul 4 channel. Output dari pin 1 relay module 4 channel masuk pada input A1 dan A2 kontaktor (Gambar 6). Pengendalian beban dilakukan melalui pin 6 digital input arduino yang mengirimkan data on/off untuk menyalakan dan mematikan beban. 


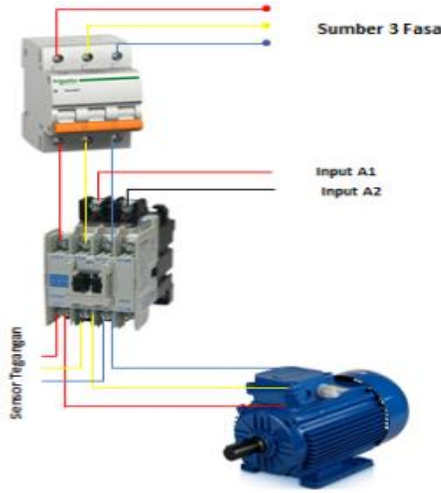

Gambar 6. Rangkaian Daya

Prinsip kerja alat dalam Gambar 7 dimulai saat alat diaktifkan. Proses inisialisasi input nilai arus dan nilai tegangan dari sensor arus dan sensor tegangan. Kemudian sensor arus dan sensor tegangan mengirim data pembacaan nilai ke arduino untuk dilakukan pengolahan data agar nilainya dapat ditampilkan pada komputer [4].

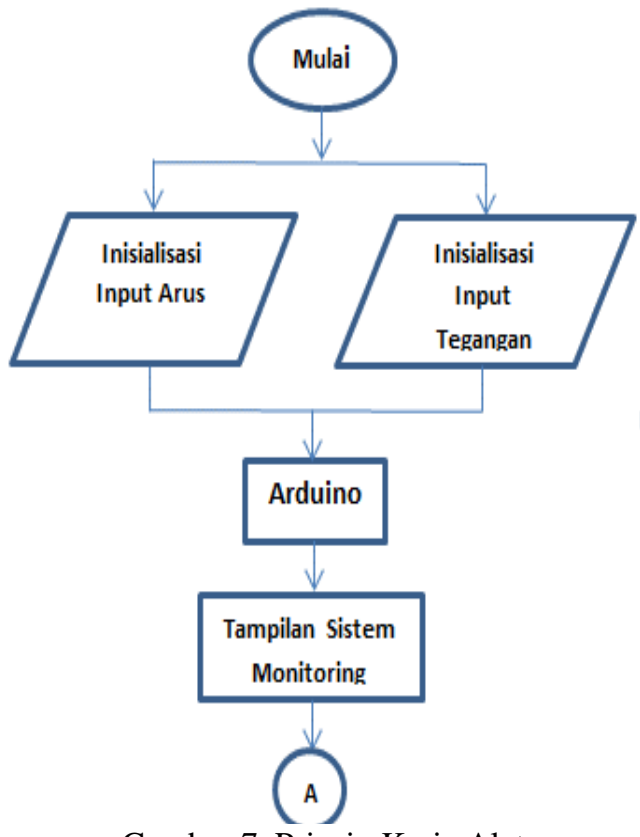

Gambar 7. Prinsip Kerja Alat

Tampilan pada komputer dapat dilakukan pengendalian yang terdiri dari tombol $O N$ dan tombol $O F F$. Ilustrasi seperti dalam Gambar 8. Proses pengendalian dilakukan dengan menekan salah satu tombol yang ada pada tampilan komputer, kemudian komputer mengirim data ke arduino untuk mengaktifkan relay, relay yang sudah aktif akan mengirimkan perintah untuk mengaktifkan kontaktor. Kontaktor tersebut akan mengaktifkan beban sesuai perintah yang dikirim, dan proses kerjapun selesai.

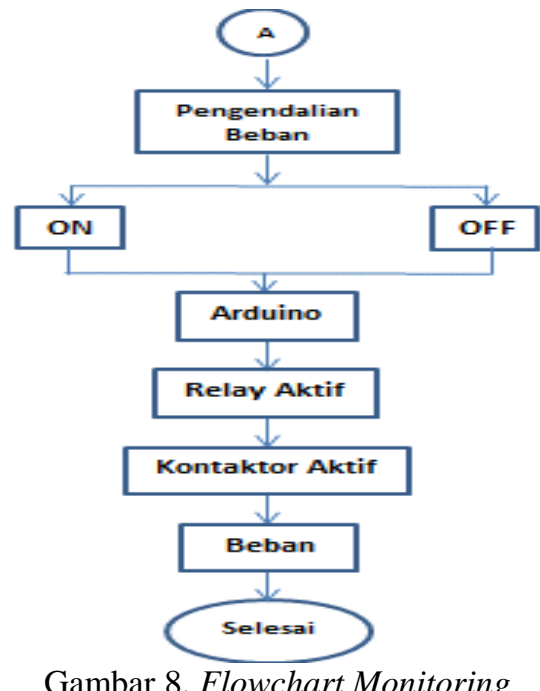

\section{Hasil Penelitian}

Pengujian rangkaian sensor tegangan bertujuan untuk mengetahui rangkaian tersebut dapat menghasilkan output yang sesuai atau tidak [5].

Pengujian sensor tegangan dengan diberi tegangan input regulaor 1 fasa yang bervariasi 25 volt, 50 volt, 75 volt, 100 volt, 125 volt, 150 volt, 175 volt, 200 volt, dan 225 volt. Hasil pengujian ditunjukkan dalam Tabel 1, dabn Gambar 9.

Tabel 1. Pengujian Sensor Tegangan

\begin{tabular}{ccc}
\hline No & $\begin{array}{c}\text { Tegangan Input } \\
\text { Regulator (VAC) }\end{array}$ & $\begin{array}{c}\text { Tegangan Output } \\
\text { Sensor (VDC) }\end{array}$ \\
\hline 1 & 25,2 & 0 \\
2 & 50,4 & 0,21 \\
3 & 75,1 & 0,8 \\
4 & 100 & 1,46 \\
5 & 125,2 & 2,15 \\
6 & 150,7 & 2,85 \\
7 & 175,2 & 3,54 \\
8 & 200,2 & 4,24 \\
9 & 225 & 4,93 \\
\hline
\end{tabular}




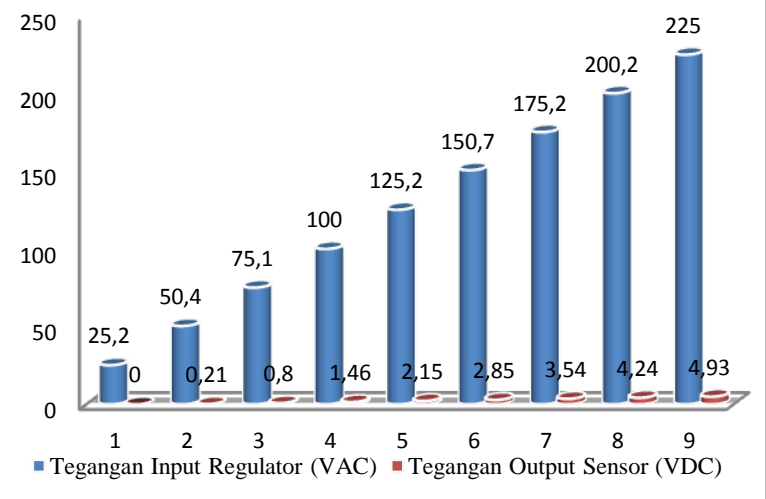

Gambar 9. Grafik Pengujian Sensor Tegangan

Pengujian alat dengan beban merupakan tahapan terakhir dalam proses pengujian alat. Tahapan ini merupakan proses penggabungan antara pengujian rangkaian dan pengujian software untuk memastikan rangkain dengan software yang sudah dibuat dapat bekerja dengan baik.

Tabel 2. Persentasi Kesalahan Pengukuran Tegangan

\begin{tabular}{llll}
\hline Tegangan & $\begin{array}{l}\text { PK } \\
\text { terendah } \\
(\boldsymbol{\%})\end{array}$ & $\begin{array}{l}\text { PK } \\
\text { Tertinggi } \\
(\boldsymbol{\%})\end{array}$ & $\begin{array}{l}\text { Rata- } \\
\text { rata PK } \\
(\boldsymbol{\%})\end{array}$ \\
\hline Fasa R & 0.08 & 1.01 & 0.48 \\
Fasa S & 1.08 & 3.45 & 2.90 \\
Fasa T & 0.06 & 3.27 & 1.39 \\
\hline
\end{tabular}

Dari data hasil pengukuran tegangan tampilan java dan data hasil pengukuran tegangan pada alat ukur, terlihat terdapat variasi nilai persentase kesalahan yang berbeda pada tiap fasanya, seperti dalam Tabel 2. Pemakaian daya listrik 3 fasa berbasis arduino mempunyai tingkat persentase kesalahan pengukuran nilai tegangan fasa $R$ sebesar $0.48 \%$, nilai tegangan fasa $S$ sebesar $2,90 \%$ dan nilai tegangan fasa $\mathrm{T}$ sebesar $1,39 \%$. Hal tersebut dipengaruhi oleh nilai inputan sensor tegangan yang masuk pada analog input pin arduino. Nilai input tegangan yang dapat menghasilkan nilai tegangan output sesuai dengan nilai pengukuran alat ukur berada pada kisaran nilai 4 Volt DC -5 Volt DC.
Tabel 3. Persentase Kesalahan Pengukuran Arus

\begin{tabular}{llll}
\hline Arus & $\begin{array}{l}\text { PK } \\
\text { terendah } \\
(\%)\end{array}$ & $\begin{array}{l}\text { PK } \\
\text { Tertinggi } \\
(\%)\end{array}$ & $\begin{array}{l}\text { Rata- } \\
\text { rata } \\
\text { PK }(\%)\end{array}$ \\
\hline Fasa $\mathbf{R}$ & 1 & 8.5 & 4.6 \\
Fasa S & 2.5 & 6.5 & 4.6 \\
Fasa T & 0.5 & 2.5 & 1.7 \\
\hline
\end{tabular}

Berdasarkan Tabel 3, hasil pengukuran arus pada tampilan java mempunyai nilai variasi yang berbeda. Persentasi kesalahan pengukuran nilai arus fasa $\mathrm{R}$ sebesar $4,6 \%$, nilai arus fasa $\mathrm{S}$ sebesar $4,6 \%$ dan nilai arus fasa $T$ sebesar $1,7 \%$. Faktor yang mempengaruhi terjadinya perbedaan nilai yang terukur pada tampilan java dengan nilai yang terukur pada alat ukur yaitu proses kalibrasi sensor arus pada arduino, dimana nilai current constanta didapat dari hasil pembagian nilai ratio terhadap nilai burden $R$ sensor arus (dalam artian jika sensor yang digunakan outpunya arus membutuhkan burden).

Sensor arus yang digunakan dalam penelitian ini merupakan tipe sensor arus yang keluaran dari sensor berupa tegangan yaitu 100A/1V. Keluaran dari sensor tersebut akan menjadi pin analog input arduino, pada arduino proses kalibrasi sensor arus dilakukan dengan menambahkan library emond lib master (library dari sensor arus). Tipe sensor arus sct $013000100 \mathrm{~A} / 1 \mathrm{~V}$ sudah terdapat burden didalamnya.

Tabel 4. Persentase Kesalahan Pengukuran Daya

\begin{tabular}{llll}
\hline Daya & $\begin{array}{l}\text { PK } \\
\text { terendah } \\
(\boldsymbol{\%})\end{array}$ & $\begin{array}{l}\text { PK } \\
\text { Tertinggi } \\
(\boldsymbol{\%})\end{array}$ & $\begin{array}{l}\text { Rata-rata } \\
\text { PK }(\boldsymbol{\%})\end{array}$ \\
\hline Fasa R & 1.23 & 8.04 & 4.49 \\
Fasa S & 0.05 & 3.39 & 2.03 \\
Fasa T & 0.34 & 4.82 & 1.93 \\
\hline
\end{tabular}

Hasil pengukuran daya masing-masing fasa, seperti dalam Tabel 4 menunjukan variasi nilai yang berbeda dengan tingkat persentasi kesalahan yang berbeda. Tingkat persentasi kesalahan pengukuran nilai daya fasa $R$ sebesar $4,49 \%$, nilai daya fasa $S$ sebesar $2,09 \%$ 
dan nilai daya fasa $T$ sebesar $1,93 \%$. Hal ini dipengaruhi hasil pengukuran daya merupakan hasil perkalian dari nilai arus dengan nilai tegangan. Nilai daya pada fasa $R$ mempunyai tingkat persentase kesalahan paling tinggi dikarenakan hasil penukuran arus pada fasa $R$ mempunyai tingkat persentasi eror yang tinggi. Untuk memperoleh hasil pengukuran daya dengan persentasi kesalahan yang rendah maka harus memperbaiki nilai arus dan nilai tegangan yang terukur pada tampilan java.

Gambar 10 dan Gambar 11 merupakan hasil dari pengujian alat dengan beban dimana data hasil pengujian disimpan pada database dengan local server secara offline.

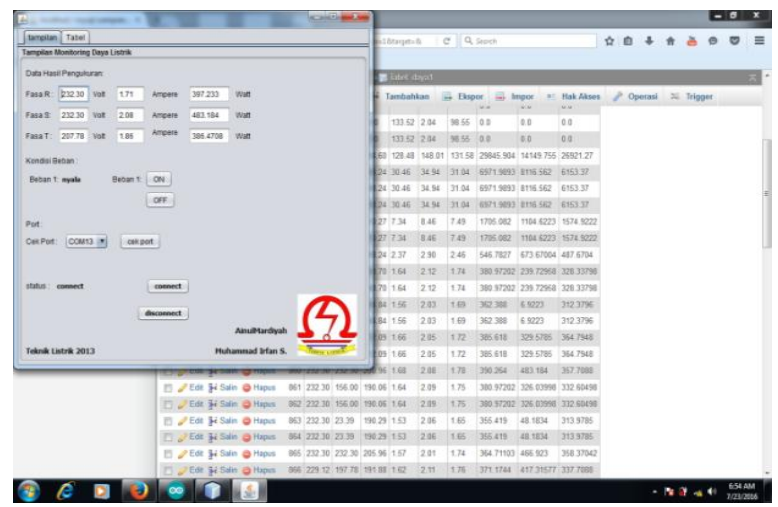

Gambar 10.Tampilan Database

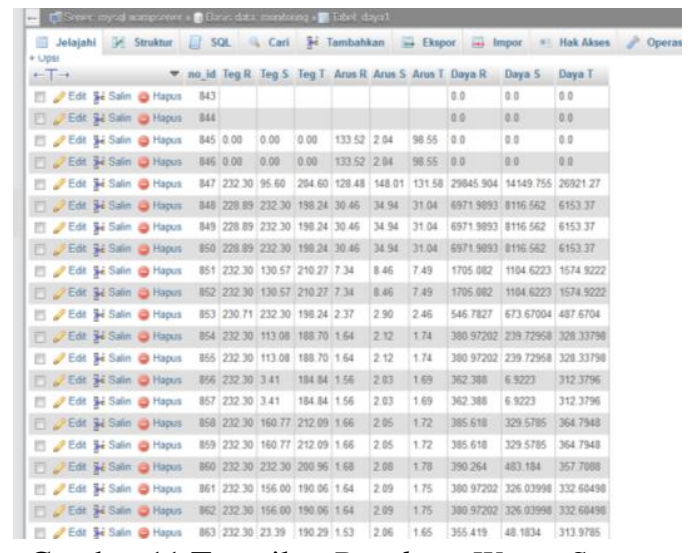

Gambar 11.Tampilan Database Wamp Server

\section{Kesimpulan}

Pemakaian daya listrik 3 fasa berbasis arduino mempunyai tingkat persentase kesalahan pengukuran nilai tegangan fasa $R$ sebesar $0,48 \%$, nilai tegangan fasa $S$ sebesar $2,90 \%$ dan nilai tegangan fasa $T$ sebesar
1,39\%. Hal tersebut dipengaruhi oleh nilai inputan sensor tegangan yang masuk pada analog input pin arduino.

Tingkat persentasi kesalahan pengukuran nilai arus fasa $R$ sebesar 4,6\%, nilai arus fasa $S$ sebesar $4,6 \%$ dan nilai arus fasa $T$ sebesar $1,7 \%$. Faktor yang mempengaruhi terjadinya perbedaan nilai yang terukur pada tampilan java dengan nilai yang terukur pada alat ukur yaitu proses kalibrasi sensor arus pada arduino.

Tingkat persentasi kesalahan pengukuran nilai daya fasa $R$ sebesar $4,49 \%$, nilai daya fasa $S$ sebesar 2,09\% dan nilai daya fasa $T$ sebesar 1,93\%. Hal ini dipengaruhi hasil pengukuran daya merupakan hasil perkalian dari nilai arus dengan nilai tegangan.

Tingkat akurasi (ketepatan) modul monitoring pemakaian daya listrik baik karena persentase kesalahan pengukuran yang dihasilkan nilainya dibawah $10 \%$.

Modul monitoring pemakaian daya listrik 3 fasa berbasis arduino dilengkapi dengan penyimpanan database mysql server offline.

\section{Saran}

Diperlukan adanya penelitian lebih lanjut mengenai pengembangan prototipe pengukuran pemakaian daya listrik dengan menambahkan beberapa variable pengukuran antar fasa dan begitu pula pada aplikasi tampilan program, sehingga akan didapatkan hasil pengukuran yang lebih akurat serta tampilan program yang lebih aplikatif.

\section{Daftar Pustaka}

[1] Perencanaan Kebutuhan Energi Sektor Industri Dalam Rangka Akselarasi Industrialisasi, Kementerian Perindustrian, Jakarta: Biro Perencanaan Kementerian Perindustrian Republik Indonesia, 2012.

[2] T. Nusa, Sistem Monitoring Konsumsi Energi Listrik Secara Real Time Berbasis Mikrokontroller. Manado: Teknik Elektro UNSRAT, 2015.

[3] R. Ibrahim, Model Pengembangan Addie. [Online] 2011. [Cited: Februari Jumat, 2017.] http://jurnalpdf.info/pdf/model- 
pengembangan-addie.html.

[4] N. Utama, Sistem Monitoring KWH Meter 3 fasa dan Kalkulasi Biaya Pemakaian. repo.pens.ac.id. [Online] 2011. [Cited: Februari Jumat, 2017.] http://repo.pens.ac.id/eprint/491.

[5] M. Iqbal, Sistem Monitoring Beban Energi Listrik Mikrokontropoller Arduino. Bandung: Universitas Pendidikan Indonesia, 2013. 